\title{
SPECT/CT for Lymphatic Mapping of Sentinel Nodes in Early Squamous Cell Carcinoma of the Oral Cavity and Oropharynx
}

\author{
Haerle Stephan K. ${ }^{1}$ and Stoeckli Sandro J. ${ }^{2}$ \\ ${ }^{1}$ Department of Otolaryngology-Head and Neck Surgery, University Hospital Zurich, Frauenklinikstrasse 24, 8091 Zurich, Switzerland \\ ${ }^{2}$ Department of Otolaryngology-Head and Neck Surgery, Kantonsspital St. Gallen, Rorschacherstraße 95, 9000 St. Gallen, Switzerland
}

Correspondence should be addressed to Stoeckli Sandro J., sandro.stoeckli@kssg.ch

Received 15 July 2010; Accepted 24 August 2010

Academic Editor: Domenico Rubello

Copyright ( $2011 \mathrm{H}$. Stephan K. and S. Sandro J. This is an open access article distributed under the Creative Commons Attribution License, which permits unrestricted use, distribution, and reproduction in any medium, provided the original work is properly cited.

\begin{abstract}
Adequate staging and treatment of the neck in squamous cell carcinoma of the oral cavity and oropharynx (OSCC) is of paramount importance. Elective neck dissection (END) of the clinical N0-neck is widely advocated as neck treatment. With regard to the prevalence of $20-40 \%$ of occult neck metastases found in the ND specimens, the majority of patients undergo surgery of the lymphatic drainage basin without therapeutic benefit. Sentinel node biopsy (SNB) has been shown to be a safe, reliable and accurate alternative treatment modality for selected patients. Using this technique, lymphatic mapping is crucial. Previous reports suggested a benefit of single photon emission computed tomography with CT (SPECT/CT) over dynamic planar lymphoscintigraphy (LS) alone. SPECT/CT allows the surgeon for better topographical orientation and delineation of sentinel lymph nodes (SLN's) against surrounding structures. Additionally, SPECT/CT has the potential to detect more SLN's which might harbour occult disease, than LS. SPECT/CT is recommended to be used routinely, although SPECT/CT is not indispensable for successful SNB.
\end{abstract}

\section{Background}

Squamous cell carcinoma of the oral cavity and oropharynx (OSCC) accounts for one of the most common cancers worldwide, with more than a quarter million new cases annually [1]. The presence or absence of lymph node involvement is of paramount importance for prognosis and therapy decision [2, 3]. Therefore, an adequate staging and management of the neck is needed. The most challenging issue remains the treatment of the clinically and radiologically negative neck. Most centers throughout the world advocate elective neck dissection (END) for histopathologic staging and removal of microscopic disease in this situation. With regard to the prevalence of $20 \%-40 \%$ of occult neck metastases found in the neck dissection specimens, the majority of patients undergo surgery of the lymphatic drainage basin without therapeutic benefit. Sentinel node biopsy (SNB) has been shown to be very accurate in selecting patients who benefit from elective neck treatment and sparing the costs and morbidity to the others. Detection of the sentinel nodes by lymphatic mapping is crucial with this technique. Single-photon emission computed tomography with CT (SPECT/CT) has been recently introduced to enhance the diagnostic accuracy of preoperative lymphoscintigraphy.

\section{Sentinel Node Biopsy}

By definition, the sentinel lymph node (SLN) is the first draining lymph node to receive lymphatic drainage from a primary tumor of a specific site [4]. In case of lymphatic spread, the lymphatic drain will first pass the SLN. All following nodes may be reached only subsequently by the disease. Therefore, selective excision of the SLN with subsequent thorough histopathologic work-up reflects adequately the nodal status of the remaining neck [5]. Since Alex and Krag [6] have described their first experience with SNB for OSCC, the technique has gained large popularity and many centers followed with validation and observational studies [7-9]. Lymphatic mapping of the SLN in the complex head and neck area has been shown to be essential [10]. The problems 
in the head and neck area are threefold: first, there is a high density of lymph nodes, second, the structure of these nodes shows an unique complexity of lymphatic pathways, and third, the SLNs are located in close proximity to the primary tumor. Therefore, sophisticated lymphatic mapping techniques are required. During the preoperative setting, a dynamic lymphoscintigraphy (LS) assesses the individual draining pattern after injection of radiolabeled particles around the primary tumor. The intraoperative use of a handheld gamma probe helps the surgeon to localise and excise the first echelon lymph nodes. The success of this technique has been abundantly reported in the literature and welldocumented guidelines do exist [11]. As with breast cancer, preliminary reports showed a new imaging technology with promising results: SPECT/CT.

\section{Patient's Selection}

For SNB of the OSCC, patients with stages I and II (T1 and T2) disease and no clinical and radiological evidence of cervical lymph node involvement are eligible. Absence of suspicious or metastatic lymph nodes is based on palpation, ultrasound with fine needle aspiration cytology (FNAC), or contrast-enhanced computed tomography (CT), or magnetic resonance imaging (MRI), or ${ }^{18}$ F-fluoro-2-deoxy-Dglucose positron emission tomography $\left({ }^{18} \mathrm{~F}-\mathrm{FDG}-\mathrm{PET}\right) / \mathrm{CT}$. With regard to conventional imaging, lymph nodes greater than $1.5 \mathrm{~cm}$ in level II and greater than $1 \mathrm{~cm}$ in all other levels, or lymph nodes with round shape, central necrosis, and peripheral contrast enhancement are considered pathologic. In metabolic imaging, a lymph node with a clearly higher FDG-uptake compared to the background and anatomically corresponding to a lymph node in the low-dose CT scan is considered pathologic.

\section{Tracer}

To assess the individual lymphatic drainage pattern, a peritumoral injection of radiolabeled particles is performed. The particles will enter the lymphatic capillaries and accumulate in the first draining node. There is a variety of colloidal and soluble tracers available although most trials report using Tc-99m-labeled human serum albumin colloid (Nanocoll, GE Healthcare). With its particle size of 8-30 nm, Nanocoll migrates to the sentinel node within minutes and remains there until the next day $[11,12]$. This allows a flexible way for planning surgery to take place.

\section{Imaging}

A standard technique for preoperative imaging is the use of a gamma camera for lymphoscintigraphy to assess the individual drainage pattern of the injected radiolabeled tracer via the capillaries to the larger collector lymphatics [13]. Imaging will be performed either the day before or the day of surgery. According to the joint practice guidelines for radionuclide lymphoscintigraphy, the setting of the camera is proposed to be as follows. A large-field-of-view gamma camera provided with a high- or ultrahigh-resolution lowenergy collimator should be used, with a 10\%-20\% window centered on the $140-\mathrm{keV}$ energy peak of Tc-99m [11]. The gamma camera should be routinely checked for quality control as proposed in published protocols [14].

Immediately after the injection of the radiotracer, the lymphatic drainage is monitored dynamically with the gamma camera in the anteroposterior projection (1 image/3 minutes). The lymphatic drainage is then observed by the nuclear medicine specialist and the HN-surgeon at the monitor. When accumulation of the radiotracer in the first echelon node(s) occurs, the dynamic imaging can be interrupted and static imaging in the anterior-posterior, lateral and, if necessary, anterior oblique view can be performed. For the different projections, a three-headed camera is recommended. To be able to localize the nodes in a three-dimensional view, static images in at least two projections are needed. The patient is imaged in the supine position with head up [11].

Most reports in the literature use the term sentinel node interchangeably for lymphoscintigraphy and SNB. As most tracer accumulations or hot spots detected by lymphoscintigraphy or SPECT/CT correspond to more than one ultimately excised sentinel lymph node, the term hot spot should be used in the context of planar imaging or fused imaging whereas sentinel lymph node should be used in the context of surgical SNB.

Intraoperatively, the surgeon will be guided to the sentinel nodes by a hand-held gamma probe containing a radiation detector with surrounding metal shielding and a collimated tip. The response related to the detected count rate is provided by a connected analyzer [11].

Using this technique, SNB has become a safe and reliable method to detect SLNs with a previously published SLN detection rate of $96 \%$ [5].

\section{SPECT/CT for Sentinel Node Mapping in HNSCC: A Comparison in the Literature}

Besides the previously described imaging technique using a preoperative lymphoscintigraphy, novel systems composed of a gamma camera and a CT scan combined in the same device have been recently introduced into clinical practice. Single photon emission CT (SPECT) and CT data are acquired at the same clinical setting without changing the patient's positioning, thus allowing for generation of accurate fused images combining the functional data of SPECT with the anatomical data of the CT scan (Figure 1). Different centers have already reported on their experience with SPECT/CT for SLN mapping in early OSCC, however, with contradictory results $[11,15-24]$. In 2000, Even-Sapir et al. described the fusion of the SPECT lymphoscintigraphy data with CT using a hybrid gamma-camera and a lowdose CT system that allows SPECT and CT to be performed at the same time without changing the patient's position [25]. Three years later, the same author introduced the hybrid SPECT/CT system into sentinel node mapping of HNSCC [15]. In 2004, two feasibility studies using planar 


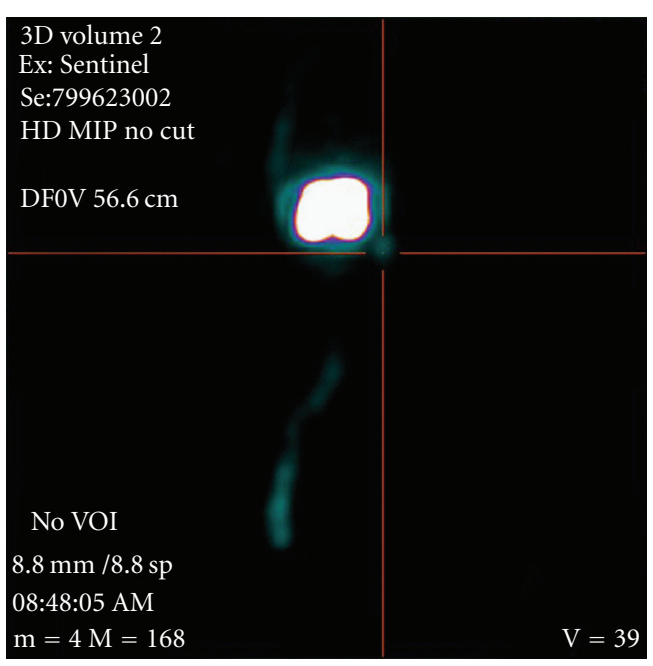

(a)

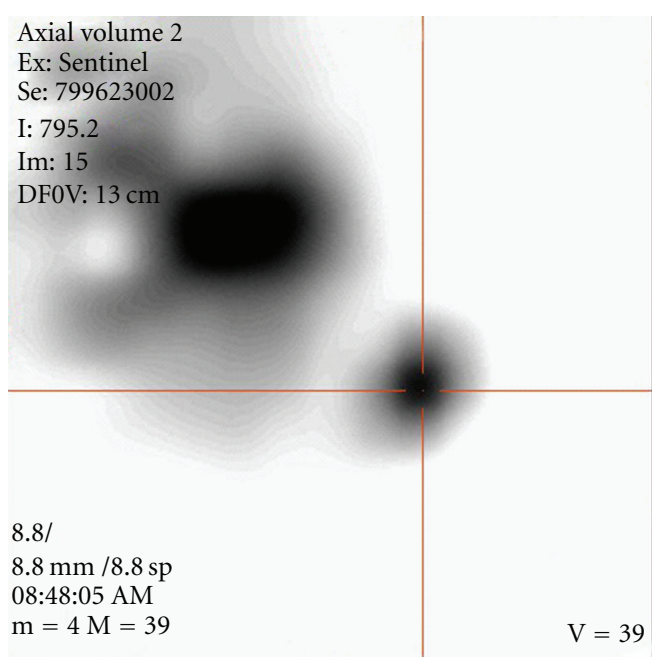

(c)

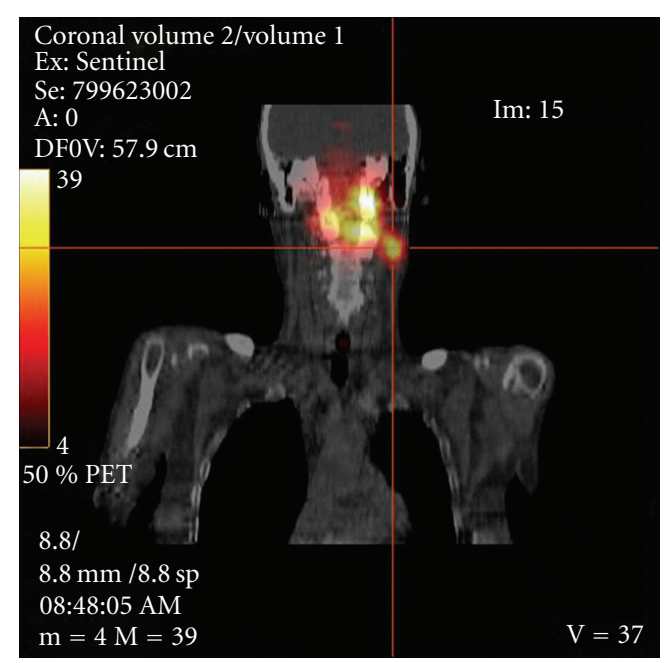

(b)

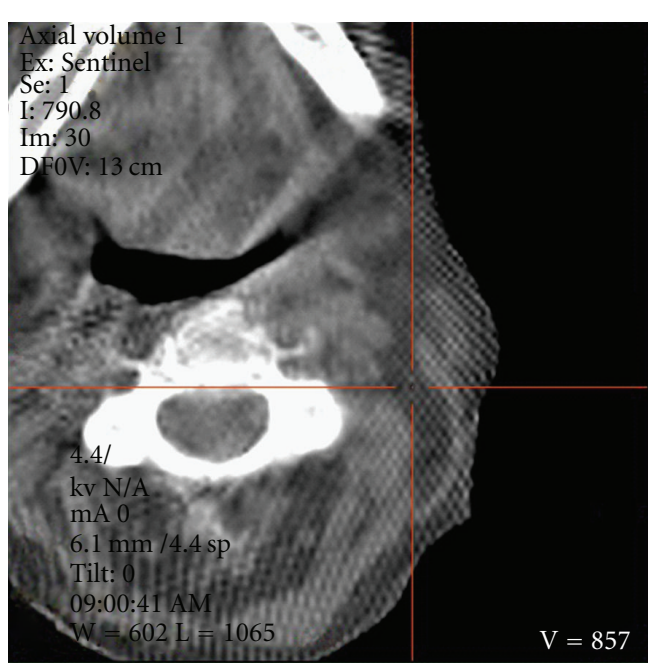

(d)

FIGURE 1: 64-year-old female suffering from a left-sided tongue cancer. (a) shows the MIP (maximum intensity projection)-image of SPECT acquisition in anteroposterior view. A large uptake is seen at the injection site with a small, focal uptake of the left lower boarder (cross hair). (b) shows a fused coronal SPECT/CT image that localises the small focal uptake in the neck region level IIA/B. (c) shows the axial SPECT image with the corresponding cross hair in the sentinel node with a clear delineation from the injection site. (d) shows the corresponding low-dose CT scan localising the uptake by linked cross hair into the neck level IIA/B.

lymphoscintigraphy and SPECT/CT were published [16, 17]. Lopez et al. included ten patients stating that they believe that SPECT/CT will become a useful tool for sentinel node mapping [16]. Wagner et al. found an additional value by using SPECT/CT for sentinel node mapping than lymphoscintigraphy alone [17]: they have found an additional lymph node nearby the submandibular gland which has only been detected by SPECT/CT. This lymph node has been overlooked by planar lymphoscintigraphy and the intraoperative gamma probe as the radioactive scattering from the primary obscured the location of the radiolabeled SLNs. The same problem has been shown by other authors in the earlier period of radioguided imaging [26,27] and was thought be resolved by introducing SPECT/CT. Thomsen et al. found SLNs close to the primary difficult to detect.
Therefore, added oblique planar images and/or tomographic scans would help to overcome this problem [18]. Terada et al. also performed a feasible study on SPECT/CT and HN mucosal carcinoma and concluded that they were able to extract all the SLNs based on the fusioned images and to confirm its radioactivity with the gamma probe without the adverse effect of overlapping radioactivity from the primary site [19]. Khafif et al. included 22 patients with biopsy proven OSCC and found an improved identification of the SLNs of $30 \%$ compared to planar imaging [20]. Bilde et al. included 34 consecutive patients with stages I and II OSCC undergoing planar lymphoscintigraphy and SPECT/CT. After all, SPECT/CT demonstrated an extra SLN in $47 \%$ compared to lymphoscintigraphy alone [21]. In the same year, KeskiSäntti et al. were the first and only authors who found 
TABLE 1: An overview of various studies using SPECT/CT in the context of lymphatic mapping for SNB in OSCC.

\begin{tabular}{|c|c|c|c|}
\hline Study group & $\begin{array}{l}\text { Number of } \\
\text { patients }(\mathrm{n})\end{array}$ & SPECT/CT and the reported detection of SLN's & $\begin{array}{l}\text { The value of SPECT/CT according to the } \\
\text { authors }\end{array}$ \\
\hline $\begin{array}{l}\text { Even-Sapir et al. } \\
{[15]}\end{array}$ & 6 & $\begin{array}{l}3 \text { additional nodes detected in } 6 \text { patients } \\
\text { compared to lymphoscintigraphy alone }\end{array}$ & $\begin{array}{l}\text { SPECT/CT adds data that is of clinical } \\
\text { relevance to SNB in patients with } \\
\text { mucosal HNSCC }\end{array}$ \\
\hline Lopez et al. [16] & 10 & $100 \%$ visualization of the SLN's by SPECT/CT & $\begin{array}{l}\text { SPECT/CT is shown to be an effective } \\
\text { method for anatomic localization of the } \\
\text { SLN's in N0 OSCC }\end{array}$ \\
\hline $\begin{array}{l}\text { Wagner et al. } \\
{[17]}\end{array}$ & 30 & $\begin{array}{l}11 \text { additional nodes out of } 49 \text { SLNs detected } \\
\text { compared to lymphoscintigraphy alone }\end{array}$ & $\begin{array}{l}\text { SPECT/CT adds additional information } \\
\text { regarding nodes that are adjacent to the } \\
\text { primary lesion }\end{array}$ \\
\hline $\begin{array}{l}\text { Thomsen et al. } \\
{[18]}\end{array}$ & 40 & $\begin{array}{l}\text { SPECT/CT and/or added oblique images } \\
\text { revealed extra nodes in } 15 / 40 \text { patients. }\end{array}$ & $\begin{array}{l}\text { SPECT/CT has added information which } \\
\text { could not have been obtained from } \\
\text { planar lymphoscintigraphy }\end{array}$ \\
\hline $\begin{array}{l}\text { Terada et al. } \\
{[19]}\end{array}$ & 15 & $100 \%$ visualization of the SLN's by SPECT/CT & $\begin{array}{l}\text { SPECT/CT proved to be an easy, } \\
\text { accurate, and reliable method }\end{array}$ \\
\hline Khafif et al. [20] & 20 & $\begin{array}{l}\text { SPECT/CT improved SLN identification } \\
\text { and/or localization compared with planar } \\
\text { images in } 6 \text { patients }(30 \%)\end{array}$ & $\begin{array}{l}\text { SPECT/CT provides additional } \\
\text { preoperative data of clinical relevance to } \\
\text { SNB in patients with OSCC }\end{array}$ \\
\hline Bilde et al. [21] & 34 & $\begin{array}{l}\text { SPECT/CT demonstrated extra SLN's } \\
\text { compared to planar imaging in } 15 \text { out of } 32 \\
\text { patients }(47 \%)\end{array}$ & $\begin{array}{l}\text { SPECT/CT detects more SLN's than } \\
\text { lymphoscintigraphy and provides } \\
\text { additional anatomical and spatial } \\
\text { information about their localization. }\end{array}$ \\
\hline $\begin{array}{l}\text { Keski-Säntti et } \\
\text { al. [22] }\end{array}$ & 15 & $\begin{array}{l}1 \text { additional SLN located in the jugular chain } \\
\text { detected compared to lymphoscintigraphy } \\
\text { alone }\end{array}$ & $\begin{array}{l}\text { SPECT/CT enables more accurate } \\
\text { localization of the SLN's, but it rarely } \\
\text { reveals SLN's, that are not detected on } \\
\text { planar images. }\end{array}$ \\
\hline Haerle et al. [23] & 58 & $\begin{array}{l}11 \text { additional hot spots could be revealed by } \\
\text { SPECT/CT compared to lymphoscintigraphy } \\
\text { alone. In one case even with additional occult } \\
\text { disease. }\end{array}$ & $\begin{array}{l}\text { SPECT/CT has the potential to detect } \\
\text { more SLN's, which might harbour occult } \\
\text { disease, than lymphoscintigraphy alone. }\end{array}$ \\
\hline
\end{tabular}

SNB: sentinel node biopsy; OSCC: oral/oropharyngeal squamous cell carcinoma; HNSCC: head and neck squamous cell carcinoma; SLN: sentinel lymph node.

no additionally revealed SLNs by SPECT/CT compared to planar imaging [22]. They concluded that despite the better topographical orientation achieved by SPECT/CT, it is not necessarily needed for preoperative lymphatic mapping. The largest single institutional cohort study was done by Haerle et al. A total of 58 patients undergoing SNB with preoperative lymphoscintigraphy and SPECT/CT have been described. Lymphoscintigraphy showed full concordance with SPECT/CT in $81 \%$ of the cases. SPECT/CT was able to detect additional HS in eleven patients, in one case even with additional metastatic disease. Therefore, in conclusion, SPECT/CT has the potential to detect more SLNs, which might harbour occult disease, than Lymphoscintigraphy alone. However, with regard to the excellent results achieved with LS and the intraoperative use of the gamma probe, SPECT/CT is not indispensable for successful SNB. The additional hot spots have all been detected in the same levels or in levels close to those in which lymphoscintigraphy has already shown hot spots. Therefore, both imaging modalities have difficulties in detecting level I sentinel nodes close to the injection site [23]. In summary, the reported series looking at preoperative sentinel node mapping for OSCC were all smaller series apart from the latter series [23]. An overview of the different series is shown in Table 1.

\section{In the Future}

Wherever applicable and affordable, SPECT/CT might become a routine preoperative imaging solution in the context of SNB for OSCC. As technical developments in SPECT/CT are ongoing [28] and high-resolution multislice CT scanners and the use of intravenous contrast will be integrated in SPECT/CT systems, even further improved spatial resolution of CT images and a better delineation of tumor adjacent structures are available. Together with the use of novel portable gamma-camera systems tested recently [29], possibly the future will provide an integrated system that combines fused imaging with an intraoperative handheld gamma-camera enabling three-dimensional visualization [30]. Apart from imaging development, new tracers may be integrated in the process of more accurate detection of the sentinel lymph nodes.

\section{Conclusions}

The technique of SNB offers a reliable, safe, and individual treatment plan for each patient's unique lymphatic drainage pattern causing low morbidity. The use of this successful technique allows the surgeon to select patients for elective 
neck dissection of the N0-neck. The use of preoperative planar lymphoscintigraphy and an intraoperative hand-held gamma probe results in excellent sentinel node-detection rates. SPECT/CT allows the surgeon for better topographical orientation and delineation of SLNs against surrounding structures, for example, muscles, vessels, and bones. Additionally, the surgical time may be reduced with regard to better spatial resolution. SPECT/CT has the potential to detect more SLNs, which might harbour occult disease, than lymphoscintigraphy alone. Therefore, we recommend using SPECT/CT routinely, although SPECT/CT is not indispensable for successful SNB.

\section{References}

[1] D. M. Parkin, F. Bray, J. Ferlay, and P. Pisani, "Global cancer statistics, 2002," CA: Cancer Journal for Clinicians, vol. 55, no. 2, pp. 74-108, 2005.

[2] D. M. Don, Y. Anzai, R. B. Lufkin, Y.-S. Fu, and T. C. Calcaterra, "Evaluation of cervical lymph node metastases in squamous cell carcinoma of the head and neck," Laryngoscope, vol. 105, no. 7, pp. 669-674, 1995.

[3] C. G. Gourin, B. T. Conger, E. S. Porubsky, W. C. Sheils, P. A. Bilodeau, and T. A. Coleman, "The effect of occult nodal metastases on survival and regional control in patients with head and neck squamous cell carcinoma," Laryngoscope, vol. 118 , no. 7, pp. 1191-1194, 2008.

[4] L. H. Sobin and C. H. Wittekind, Eds., TNM Classification of Malignant Tumors, John Wiley \& Sons, New York, NY, USA, 6th edition, 2002.

[5] S. J. Stoeckli, "Sentinel node biopsy for oral and oropharyngeal squamous cell carcinoma of the head and neck," Laryngoscope, vol. 117, no. 9, pp. 1539-1551, 2007.

[6] J. C. Alex and D. N. Krag, "The gamma-probe-guided resection of radiolabeled primary lymph nodes," Surgical Oncology Clinics of North America, vol. 5, no. 1, pp. 33-41, 1996.

[7] J. C. Alex, C. T. Sasaki, D. N. Krag, B. Wenig, and P. B. Pyle, "Sentinel lymph node radiolocalization in head and neck squamous cell carcinoma," Laryngoscope, vol. 110, no. 2, pp. 198-203, 2000.

[8] T. Shoaib, D. S. Soutar, J. E. Prosser et al., "A suggested method for sentinel node biopsy in squamous cell carcinoma of the head and neck," Head and Neck, vol. 21, no. 8, pp. 728-733, 1999.

[9] S. J. Stoeckli, H. Steinert, M. Pfaltz, and S. Schmid, "Sentinel lymph node evaluation in squamous cell carcinoma of the head and neck," Otolaryngology-Head and Neck Surgery, vol. 125, no. 3, pp. 221-226, 2001.

[10] G. L. Ross, D. S. Soutar, T. Shoaib et al., "The ability of lymphoscintigraphy to direct sentinel node biopsy in the clinically N0 neck for patients with head and neck squamous cell carcinoma," British Journal of Radiology, vol. 75, no. 900, pp. 950-958, 2002.

[11] L. W. T. Alkureishi, Z. Burak, J. A. Alvarez, et al., "Joint practice guidelines for radionuclide lymphoscintigraphy for sentinel node localization in oral/oropharyngeal squamous cell carcinoma," Annals of Surgical Oncology, vol. 16, no. 11, pp. 3190-3210, 2009.

[12] A. J. Wilhelm, G. S. Mijnhout, and E. J. F. Franssen, "Radiopharmaceuticals in sentinel lymph-node detection-an overview," European Journal of Nuclear Medicine, vol. 26, pp. S36-S42, 1999.
[13] S. Modi, A. W. B. Stanton, P. S. Mortimer, and J. R. Levick, "Clinical assessment of human lymph flow using removal rate constants of interstitial macromolecules: a critical review of lymphoscintigraphy," Lymphatic Research and Biology, vol. 5, no. 3, pp. 183-202, 2007.

[14] IEC/TR 61948-2 Ed. 1.0, "Nuclear medicine instrumentationRoutine tests-Part 2: scintillation cameras and single photon emission computed tomography imaging," Tech. Rep., International Electrotechnical Commission, Geneva, Switzerland, 2001.

[15] E. Even-Sapir, H. Lerman, G. Lievshitz et al., "Lymphoscintigraphy for sentinel node mapping using a hybrid SPECT/CT system," Journal of Nuclear Medicine, vol. 44, no. 9, pp. 14131420, 2003.

[16] R. Lopez, P. Payoux, P. Gantet, J. P. Esquerré, F. Boutault, and J. R. Paoli, "Multimodal image registration for localization of sentinel nodes in head and neck squamous cell carcinoma," Journal of Oral and Maxillofacial Surgery, vol. 62, no. 12, pp. 1497-1504, 2004.

[17] A. Wagner, K. Schicho, C. Glaser et al., "SPECT-CT for topographic mapping of sentinel lymph nodes prior to gamma probe-guided biopsy in head and neck squamous cell carcinoma," Journal of Cranio-Maxillofacial Surgery, vol. 32, no. 6, pp. 343-349, 2004.

[18] J. B. Thomsen, J. A. Sørensen, P. Grupe, and A. Krogdahl, "Sentinel lymph node biopsy in oral cancer: validation of technique and clinical implications of added oblique planar lymphoscintigraphy and/or tomography," Acta Radiologica, vol. 46, no. 6, pp. 569-575, 2005.

[19] A. Terada, Y. Hasegawa, M. Goto et al., "Sentinel lymph node radiolocalization in clinically negative neck oral cancer," Head and Neck, vol. 28, no. 2, pp. 114-120, 2006.

[20] A. Khafif, S. Schneebaum, D. M. Fliss et al., "Lymphoscintigraphy for sentinel node mapping using a hybrid single photon emission CT (SPECT)/CT system in oral cavity squamous cell carcinoma," Head and Neck, vol. 28, no. 10, pp. 874-879, 2006.

[21] A. Bilde, C. Von Buchwald, J. Mortensen et al., "The role of SPECT-CT in the lymphoscintigraphic identification of sentinel nodes in patients with oral cancer," Acta OtoLaryngologica, vol. 126, no. 10, pp. 1096-1103, 2006.

[22] H. Keski-Säntti, S. Mätzke, T. Kauppinen, J. Törnwall, and T. Atula, "Sentinel lymph node mapping using SPECT-CT fusion imaging in patients with oral cavity squamous cell carcinoma," European Archives of Oto-Rhino-Laryngology, vol. 263, no. 11, pp. 1008-1012, 2006.

[23] S. K. Haerle, T. F. Hany, K. Strobel, D. Sidler, and S. J. Stoeckli, "Is there an additional value of spect/ct over planar lymphoscintigraphy for sentinel node mapping in oral/oropharyngeal squamous cell carcinoma?" Annals of Surgical Oncology, vol. 16, no. 11, pp. 3118-3124, 2009.

[24] L. Vermeeren, W. M. C. Klop, M. W. M. van den Brekel, A. J. M. Balm, O. E. Nieweg, and R. A. Valdés Olmos, "Sentinel node detection in head and neck malignancies: innovations in radioguided surgery," Journal of Oncology, vol. 2009, Article ID 681746, 10 pages, 2009.

[25] E. Even-Sapir, Z. Keidar, J. Sachs et al., "The new technology of combined transmission and emission tomography in evaluation of endocrine neoplasms," Journal of Nuclear Medicine, vol. 42, no. 7, pp. 998-1004, 2001.

[26] W. M. Koch, M. A. Choti, A. C. Civelek, D. W. Eisele, and J. R. Saunders, "Gamma probe-directed biopsy of the sentinel node in oral squamous cell carcinoma," Archives of Otolaryngology-Head and Neck Surgery, vol. 124, no. 4, pp. 455-459, 1998. 
[27] D. R. Colnot, E. J. C. Nieuwenhuis, M. W. M. van den Brekel et al., "Head and neck squamous cell carcinoma: us-guided fine-needle aspiration of sentinel lymph nodes for improved staging —initial experience," Radiology, vol. 218, no. 1, pp. 289-293, 2001.

[28] A. K. Buck, S. Nekolla, S. Ziegler et al., "SPECT/CT," Journal of Nuclear Medicine, vol. 49, no. 8, pp. 1305-1319, 2008.

[29] L. Vermeeren, R. A. Valdés Olmos, W. M. Klop, A. J. Balm, and M. W. van den Brekel, "A portable gamma-camera for intraoperative detection of sentinel nodes in the head and neck region," Journal of Nuclear Medicine, vol. 51, no. 5, pp. 700703, 2010.

[30] T. Wendler, A. Hartl, T. Lasser et al., "Towards intra-operative $3 \mathrm{D}$ nuclear imaging: reconstruction of $3 \mathrm{D}$ radioactive distributions using tracked gamma probes," Medical Image Computing and Computer-Assisted Intervention, vol. 10, no. 2, pp. 909-917, 2007. 


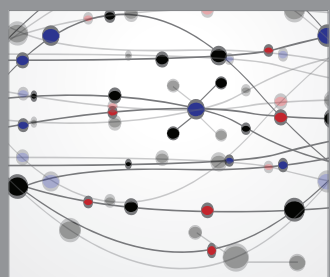

The Scientific World Journal
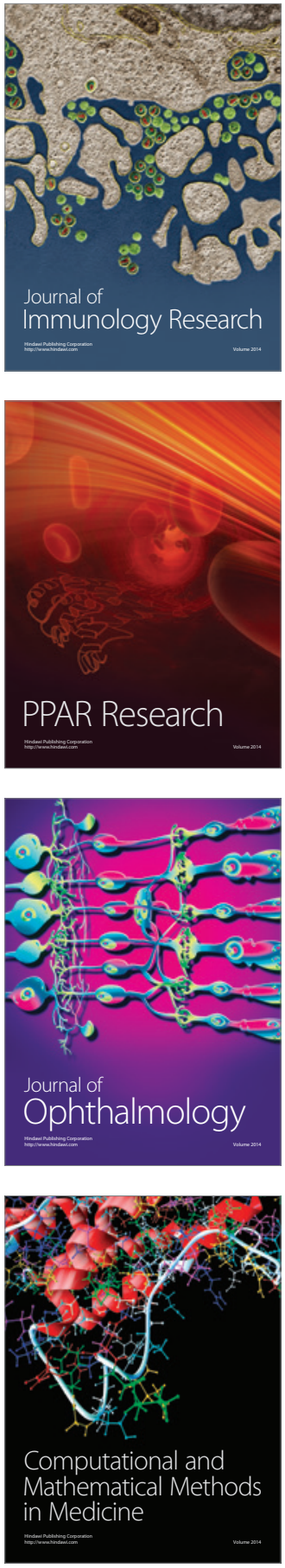

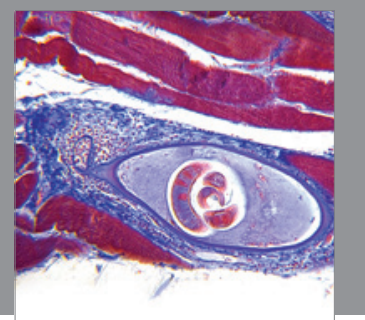

Gastroenterology

Research and Practice
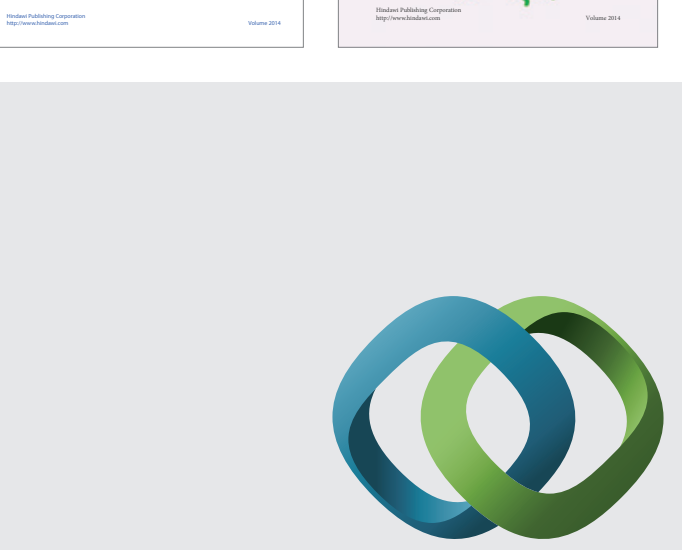

\section{Hindawi}

Submit your manuscripts at

http://www.hindawi.com
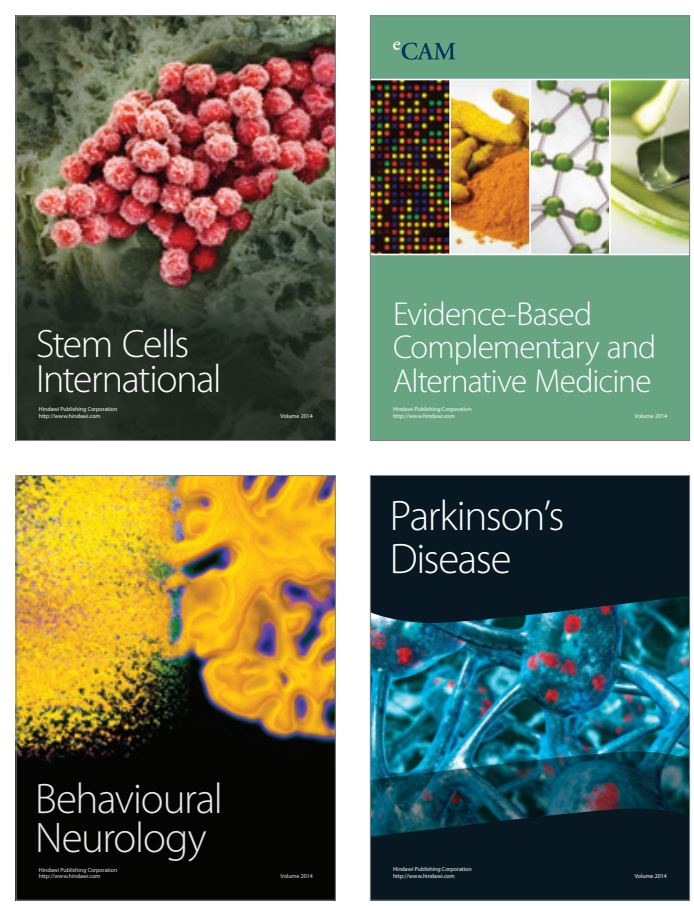

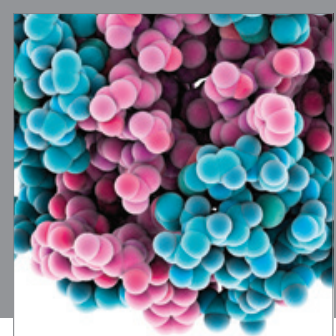

Journal of
Diabetes Research

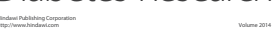

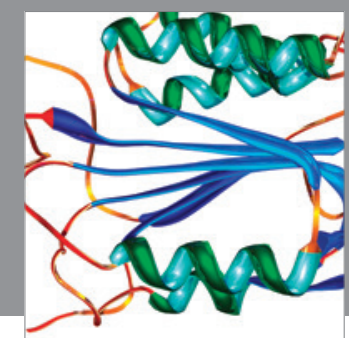

Disease Markers
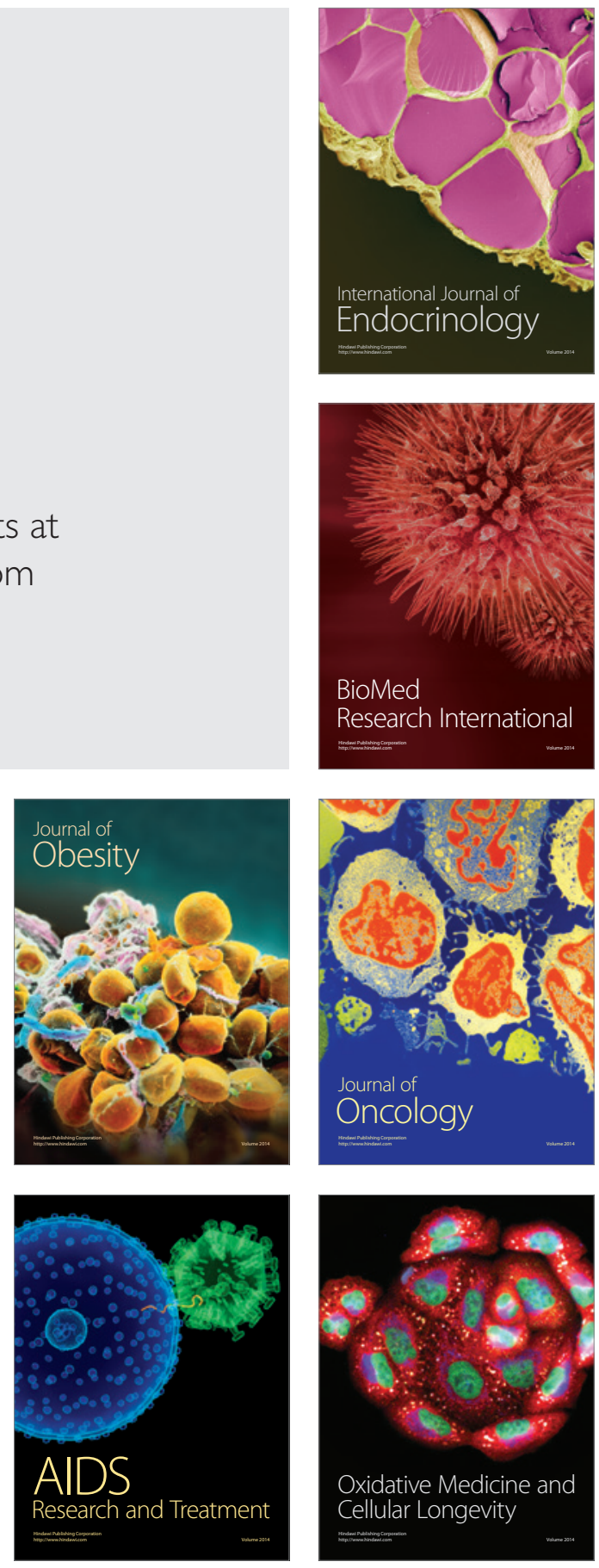